\title{
Fabrication and Characterization of Nano Hybrid Cellulose Acetate-nanoTiO,/crosslinked Polyvinyl Alcohol Coated Membrane for Crude Clove Oil Purification
}

\author{
Tutuk Djoko Kusworo' ${ }^{1,2}$, Widayat Widayat ${ }^{1}$, Dani Puji Utomo ${ }^{1}$ \\ ${ }^{1}$ Chemical Engineering Department, Faculty of Engineering, Diponegoro University, \\ Jl. Prof. H. Soedarto, S.H., Tembalang, Kota Semarang, Jawa Tengah, 50275, Indonesia \\ ${ }^{2}$ Center of Exellent Membrane, Membrane Research Center (MeR-C), Diponegoro University, \\ JI. Prof. H. Soedarto, S.H., Tembalang, Kota Semarang, Jawa Tengah, 50275, Indonesia \\ *Corresponding author, e-mail: tdkusworo@che.undip.ac.id
}

Received: 12 February 2019, Accepted: 14 May 2019, Published online: 02 July 2019

\begin{abstract}
The application of membranes for clove oil purification has the potential to improve the efficiency and effectiveness of processing. The main problem that occurs is the polymer-based membranes tend to change in properties such as weakening, dissolving, and swelling when contact with clove oil. In this study, cellulose acetate membrane was developed with $\mathrm{TiO}_{2}$ nano-particles to reduce swelling effect and coating with polyvinyl alcohol (PVA) to modify membrane surface. The membranes were prepared using dry-wet phase inversion method from dope solution with polymer concentration of $14-20 \mathrm{wt} \%$ and nano-particles of $\mathrm{TiO}_{2}$ with a concentration of 0-1.5 wt\% in total solid. The formed membrane was coated with PVA with a concentration of 2-5 wt\% crosslinked using glutaraldehyde. The SEM results show that prepared membrane are asymmetric membranes and show the coated layer of PVA on the surface. The FTIR spectra confirm that the PVA is successfully crosslinked and the addition of nano-particles $\mathrm{TiO}_{2}$ decreases the membrane swelling degree,

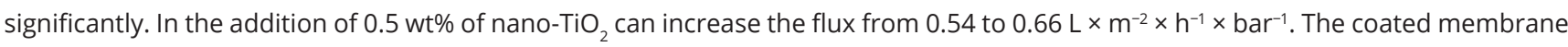
surface using PVA increases the selectivity of the membrane to produce clove oil permeates with eugenol content of $82.5 \%$ from $68 \%$.
\end{abstract} Keywords

cellulose acetate, clove oil, crosslinking, hybrid membrane, nano $\mathrm{TiO}_{2}$, polyvinyl alcohol

\section{Introduction}

Chemical separation and purification technology is a very important part in the chemical industry because this section determines the quality of the product. In general, the separation process requires $70 \%$ of all energy costs in a chemical plant [1]. Separation technologies such as distillation, extraction and absorption generally require phase change and solvent removal by heating so that the main weakness in this process is the high energy consumption [2]. Such separation processes have been commonly applied in the purification of essential oils such as clove oil, patchouli oil, ginger oil, phenolic compound, and other essential oils [3-5]. The introduction of membrane separation for bioproduct extraction was massively studied [6-7]. However, recent separation technologies such as polymeric based membranes were rarely applied in the purification of essential oils.

Polymeric based membranes have several advantages including the range of separation from molecular to particulate, operation process at mild conditions, and easy to be scaled-up or scaled-down. However, the membrane also has some disadvantages: it is easy to cause fouling and decrease the productivity drastically; incompatibilities of membrane material with some chemicals that cause swelling, dissolved, or weaken [8-9].

The development and use of organic solvent nanofiltration (OSN) membranes to concentrate various precious chemicals in essential oils is still relatively small. Peev et al. [10] developed an OSN membrane to concentrate rosmarinic acid extract from lemon oil. Several other studies have also reported membrane applications for the removal of waxes in various essential oils [11-12]. Other studies related to the purification of essential oils were reported by Tylkowski et al. [13] using an OSN membrane to concentrate extracts of ethanolic compounds from propolis and Carlson et al. [14] applied reverse osmosis 
membranes to separate supercritical carbon dioxide from limonene. Sarmento et al. [15] also reported the application of membrane to concentrate essential oils derived from supercritical processes. However, the use of membranes for clove oil purification in the recent days has not been widely studied. The only literature which studies about the application of polymeric membrane for clove oil purification is reported by Nasution et al. [16]. They used a cellulose-chitosan membrane to purify clove oil, the result obtained was a 2.5 bar trans-membrane pressure resulting in a permeate flux of $0.239 \mathrm{~L} / \mathrm{m}^{2} . \mathrm{sec}$ with the highest eugenol level achieved was $58.21 \%$.

The phenomenon of swelling on the membrane decreases the membrane performance so that it needs a solution to overcome this problem [17]. In addition, eugenol and $\beta$-caryophyllene molecules have almost the same molecular size when viewed from their molecular weight, which is 164.2 Da for eugenol and 204.3 Da for $\beta$-caryophyllene. Separation using membranes becomes less effective when the size exclusion mechanism separation is used. As shown in Fig. 1, there is a significant chemical potential difference between eugenol and $\beta$-caryophyllene. Eugenol has functional groups of (-OH) and (-O-) while $\beta$-caryophyllene is surrounded by methyl groups $\left(-\mathrm{CH}_{3}\right)$ and methylene $\left(=\mathrm{CH}_{2}\right)$. Based on their chemical molecular structure, eugenol is much more hydrophilic than $\beta$-crayophyllene. Hence, to maximize separation efficiency it is necessary to make membrane with a certain degree of hydrophilicity to produce maximum selectivity [18].

In this study hybrid membranes were developed by incorporating nano- $\mathrm{TiO}_{2}$ material which is expected to overcome the swelling problem, besides the addition of nano- $\mathrm{TiO}_{2}$ has been reported to increase solvent permeability in OSN membrane applications and it has super-hydrophilic nature properties [19-21]. To improve the hydrophilicity of the CA membrane as well as its mechanical

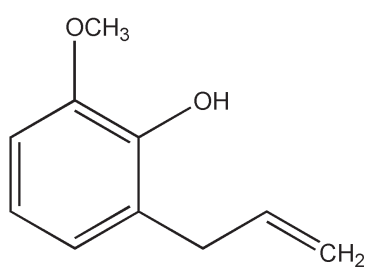

(a)

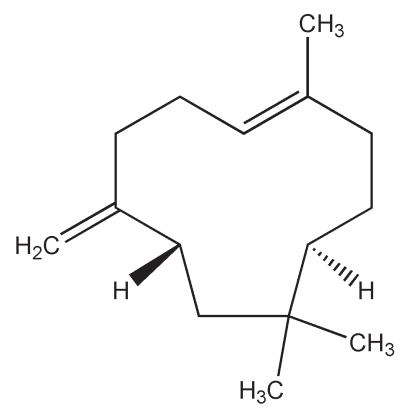

(b)
Fig. 1 Molecular structure of (a) eugenol, (b) $\beta$-caryophyllene strength, the membrane surface is modified using polyvinyl alcohol (PVA) polymers because they are tolerant to various chemicals [22-23]. To our knowledge, there is no report on the use of cross-linked PVA to modify CA-TiO membrane surface for purifying cloves leaf oil.

\section{Materials and Methods}

\subsection{Materials}

Crude cloves leaf oil was obtained from clove farms in Semarang, Indonesia. Cellulose acetate (CA) polymers were purchased from Alpha Chemicals, India, with an average molecular weight of $30 \mathrm{kDa}$ and acetate content of 53-56 \%. Nano-particles $\mathrm{TiO}_{2}$ was supplied from Nano Center Indonesia, Tangerang. Polyvinyl alcohol (PVA) was purchased from Brataco Chemical, Indonesia. Industrial grade nitrogen gas purity $>99 \%$ purchased from Aneka Gas, Ltd., Indonesia. Other chemicals such as polyethylene glycol (PEG), glutaraldehyde, acetone, sulfuric acid, sodium hydroxide, and hydrochloric acid were purchased from Indrasari, Ltd. and Multi Kimia Raya, Ltd., Indonesia.

\subsection{Fabrication of neat CA membrane and hybrid CA- $\mathrm{TiO}_{2}$ membranes}

Membranes fabrications were conducted by preparing dope polymer solution consisting of CA polymers, additives, and acetone as solvents [24-25]. The dope membrane solution was prepared with a polymeric composition as shown in Table 1. The dope solution was stirred for $24 \mathrm{~h}$ using a magnetic stirrer to obtain a homogeneous solution. Furthermore, the solution is allowed to stand for another $24 \mathrm{~h}$ to remove air bubbles trapped in solution.

Table 1 Formulation of membrane dope solution composition

\begin{tabular}{lccc}
\hline $\begin{array}{l}\text { Membrane } \\
\text { code }\end{array}$ & $\begin{array}{c}\text { CA } \\
(\%)\end{array}$ & $\begin{array}{c}\text { TiO } \\
(\%)\end{array}$ & $\begin{array}{c}\text { PVA } \\
(\%)\end{array}$ \\
\hline M1 & 14 & 0 & 0 \\
M2 & 16 & 0 & 0 \\
M3 & 18 & 0 & 0 \\
M4 & 20 & 0 & 0 \\
M5 & 18 & 0.1 & 0 \\
M6 & 18 & 0.5 & 0 \\
M7 & 18 & 1 & 0 \\
M8 & 18 & 1.5 & 0 \\
M9 & 18 & 0.5 & 2 \\
M10 & 18 & 0.5 & 3 \\
M11 & 18 & 0.5 & 4 \\
M12 & 18 & 0.5 & 5 \\
\hline
\end{tabular}


The dope solution for $\mathrm{CA} / \mathrm{TiO}_{2}$ membrane was prepared by adding nano- $\mathrm{TiO}_{2}$ (as shown in Table 1) to the acetone solvent. The mixture is then sonicated for 60 minutes. Membranes were casted via dry-wet phase inversion technique. Furthermore, the membrane film was casted using casting knife with a thickness of $150 \mu \mathrm{m}$. A thin layer of membrane over the glass is allowed to stand for $30 \mathrm{sec}-$ onds for dry-coagulation process. Furthermore, the membrane layer is immersed in a coagulation bath containing deionized water at room temperature for $1 \mathrm{~h}$ followed by immersion in another coagulation bath for $24 \mathrm{~h}$ to ensure all solvents were removed from the membrane. The membrane is then dried in an oven of $40-50{ }^{\circ} \mathrm{C}$ for $24 \mathrm{~h}$.

\subsection{CA membrane coating using crosslinked PVA}

Coating process was performed using dip-coating technique followed by cross-linking as reported by $\mathrm{Yu}$ et al. [26]. The PVA polymer was dissolved into deionized water at $90{ }^{\circ} \mathrm{C}$. with concentrations according to Table 1 . Thereafter the PVA solution was used to coat the $\mathrm{CA}-\mathrm{TiO}_{2}$ membrane using a dip-coating technique. The upper side of the $\mathrm{CA}-\mathrm{TiO}_{2}$ membrane was immersed in PVA solution for an $\mathrm{h}$ then dried in oven at $40-50{ }^{\circ} \mathrm{C}$ for $24 \mathrm{~h}$. To reduce swelling of the membrane, the PVA-coated $\mathrm{CA}-\mathrm{TiO}_{2}$ was then immersed in a cross-link agent solution containing $5 \mathrm{wt} \%$ of glutaraldehyde and $0.5 \mathrm{wt} \%$ of $\mathrm{H}_{2} \mathrm{SO}_{4}$ for $2 \mathrm{~min}$. The coated membrane was dried in an oven with a temperature of $50{ }^{\circ} \mathrm{C}$ for $2 \mathrm{~h}$.

\subsection{Membrane characterization using scanning electron microscope}

Morphology of surface and cross-sectional structure of the membrane was performed using SEM as reported by Chakrabarty et al. [27]. The membrane was dried first and then immersed in ethanol for $1 \mathrm{~h}$ to swell the membrane. Then the membrane was immersed in liquid nitrogen for a few seconds until it become brittle. In order to obtain high quality of cross-section image, the membrane was fractured using tweezers. This piece of membrane is coated with pure gold (coating) that serves as a conductor. Furthermore, cross-section and membrane surfaces were scanned with certain magnifications.

\subsection{Membrane characterization using fourier transform infra-red}

Membrane characterization using FTIR was used to determine functional groups on the membrane. This test is conducted to determine the effect of adding PEG and
PVA. A number of membrane samples $(2 \times 4 \mathrm{~cm})$ were crushed together with $\mathrm{KBr}$ pellets. Samples were then analyzed using an FTIR tool with a wavelength range between 4000 to $300 \mathrm{~cm}^{-1}$ [28].

\subsection{Membrane characterization using X-ray diffraction} The membrane and nanoparticle crystallinity phases of $\mathrm{TiO}_{2}$ were analyzed using X-Ray diffraction (Bucker D8, Germany). X-rays are emitted from the $\mathrm{Cu} \mathrm{K} \alpha$ monochromatic cathode operated at $300 \mathrm{~mA}$ and $400 \mathrm{kV}$ from angle

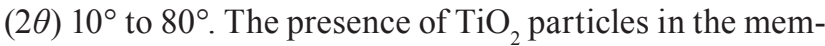
brane is confirmed by analyzing identical peaks to typical peak-owned $\mathrm{TiO}_{2}$ particles.

\subsection{Determination of $\mathrm{MWCO}$, average pore radius, and porosity}

MWCO characterization of the membranes that have been prepared can be used to estimate the average size of membrane pores. The MWCO membrane shows the molecular weight of the solute rejected by the membrane by $90 \%$. The determination of the MWCO value using PEG has been reported by Panda and De [29]. MWCO value of membranes were determined by making a PEG solution having different molecular weights with a concentration of $5 \%$. The PEG solution is then filtered using a membrane in a dead-end membrane filtration system. The solute rejection was calculated by analyzing the PEG content of the permeate using a refractometer. Rejection value is plotted against molecular weight. The molecular weight corresponding to the $90 \%$ rejection of the solute is defined as the MWCO membrane. The MWCO value can be used to predict pore size of the membrane through solute transport method by using Eq.(1) [30].

$r_{m}(\mathrm{~cm})=16.73 \times 10^{-10}(\mathrm{MWCO})^{0.557}$

Another parameter that also has an important contribution in determining membrane performance is porosity. Membrane porosity is defined as the fraction of the volume of empty space in the membrane to the total volume of the membrane. To determine porosity, membranes of a certain size are immersed in ion-free water for 24 hours [31]. The subsequent membrane was weighed after wiping using tissue paper. The membrane is then dried in a $60{ }^{\circ} \mathrm{C}$ oven for $24 \mathrm{~h}$ and fed into the desiccator before weighing. Membrane porosity is calculated by Eq.(2).

$\varepsilon=\frac{w_{0}-w_{i}}{\rho_{\text {air }} A \times l}$ 
With $\varepsilon=$ membrane porosity, $w_{0}$ and $w_{i}$ were the weight of the membrane before and after dried (gr). $A=$ the effective area of the membrane $\left(\mathrm{cm}^{2}\right), l=$ the thickness of the membrane $(\mathrm{cm})$, and $\rho_{\text {water }}=$ the density of water at room temperature $\left(\mathrm{gr} / \mathrm{cm}^{3}\right)$.

\subsection{Water contact angle measurement}

Water contact angle of the membrane that has been made needs to be analyzed even though the membrane is not used in water treatment. Hugging the contact angle is useful for viewing membrane hydrophilicity. The membrane hydrophilicity properties determine the efficiency of separation between eugenol and $\beta$-caryophyllene. Measurement of water contact angles on the surface of the object was introduced to observe the surface tension. Ion-free water is used as a probe liquid and when ion free water is dripped over the membrane surface, water contact angles are measured immediately using a water contact angle meter on three or five left and right-side points.

\subsection{Membrane swelling degree measurement}

Measurement of swelling degree was performed by gravimetric method which was developed by $\mathrm{Yi}$ and Bae [32]. Samples of membranes $(5 \mathrm{~cm} \times 5 \mathrm{~cm})$ were dried in oven at $50{ }^{\circ} \mathrm{C}$ temperature for $1 \mathrm{~h}$ then weighed as dry membrane weight $\left(W_{0}\right)$. The membrane samples were then immersed in eugenol and then weighed every $1 \mathrm{~h}$ for $4 \mathrm{~h}$ to obtain a mass of swollen membrane $\left(W_{i}\right)$. The degree of swelling was expressed as the ratio of membrane volume changes with Eq. (3):

$$
\frac{V_{i}}{V_{0}}=\frac{\left(W_{0} / \rho_{\text {mem }}\right) \times\left[\left(W_{i}-W_{0}\right) / \rho_{\text {eug }}\right]}{W_{0} / \rho_{0}} .
$$

$V_{i}$ and $V_{0}$ were the membrane volumes under swelling conditions and initial conditions. $W_{0}$ and $W_{i}$ were the mass of dry membrane and swollen membrane with solvent. $\rho_{\text {mem }}$, $\rho_{\text {eug }}$, and $\rho_{0}$ were membrane densities of swollen membrane without solvent, eugenol, and dry membrane. In this study, $\rho_{\text {mem }}$ and $\rho_{0}$ were assumed to be the same.

\subsection{Procedure of clove oil quality analysis}

Quality parameters of clove oil are the specific gravity, refractive index, solubility in alcohol, total eugenol content, and $\beta$-caryophyllene content. In accordance with the standard method of SNI 06-2387-2006 [33], the specific gravity of clove oil was measured using a pycnometer at $20{ }^{\circ} \mathrm{C}$. The refractive oil index of clove was determined using a refractometer at $20^{\circ} \mathrm{C}$. Total eugenol content was determined by reacting $5 \mathrm{ml}$ of clove oil sample with $10 \mathrm{~mL}$ of $\mathrm{KOH}$ or $\mathrm{NaOH} 4 \%$. Shake the solution for $30 \mathrm{~min}$ then add another $4 \% \mathrm{KOH}$ or $\mathrm{NaOH}$ for $10 \mathrm{~mL}$ then heated in water bath for $10 \mathrm{~min}$. After the two layer was formed, the top layer solution was separated. Moreover, The bottom layer was added with a few drops of concentrated $\mathrm{HCl}$ to form two layers. The bottom layer (eugenol) was separated and then measured its volume. Total eugenol content was the percentage eugenol volume in total volume of clove oil sample.

\subsection{Membrane performance test}

Membrane performance was evaluated from the flux and total concentration of eugenol in clove oil permeates. Clove oil filtration using membranes was performed in a dead-end filtration system according to Fig. 2. The prepared membrane was placed on a membrane holder with an effective cross-sectional area of $15.20 \mathrm{~cm}^{2}$. Install the rubber seal over the membrane then attach the stainless-steel cylinder above the membrane as sample chamber. Cover the cylinder and tighten the bolts on the cylinder cover. The cloves leaf oil sample was dissolved in a carrier solvent (n-hexane) with a concentration of $75 \mathrm{wt} \%[12,34]$. A membrane filtration device was connected with the hose from a gas cylinder. Open the gas regulator and set the upstream pressure around 5 bars. Observe and record the permeate volume after filtration run for 1 hour. The permeate flux was calculated using Eq. (4) as follows:

$$
J=\frac{V}{P \times A \times t} .
$$

With $J=$ the flux $\left(\mathrm{Lm}^{-2} \mathrm{~h}^{-1} \mathrm{bar}^{-1}\right), V=$ the permeate volume (L), $P=$ the transmembrane pressure (bar), $A=$ the effective area of the membrane $\left(15.20 \mathrm{~cm}^{2}\right)$, and $t=$ the operatingtime (h).

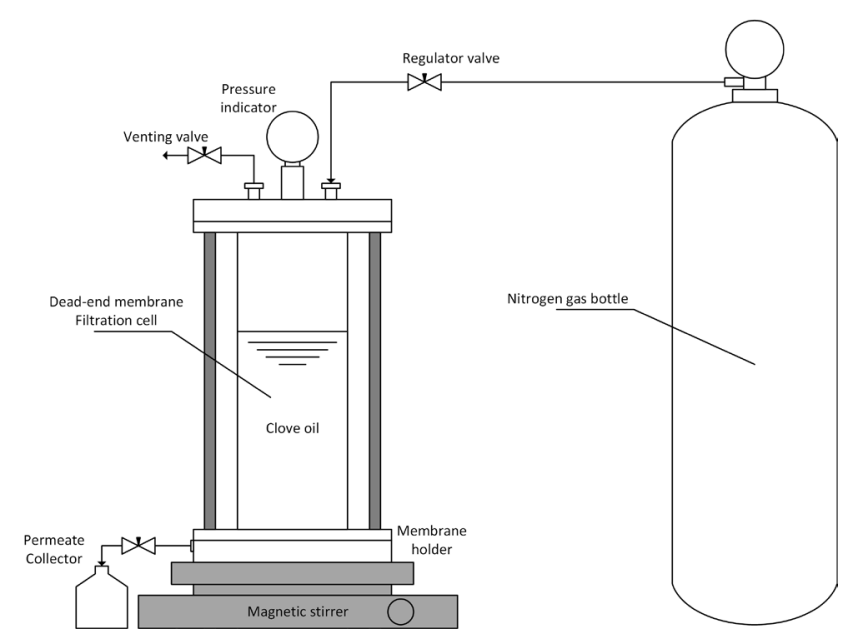

Fig. 2 Dead-end membrane filtration equipment 
To observe the membranes performances in term of separation efficiency, the cloves leaf oil sample and permeate were analyzed their eugenol content. Solvent in permeate was removed by means of being heated in an oven at $50{ }^{\circ} \mathrm{C}$ for $8 \mathrm{~h}$. As much as $2 \mathrm{~mL}$ of permeate sample was put into the reaction tube then $10 \mathrm{~mL}$ of $\mathrm{NaOH} 1 \mathrm{~N}$ was added. The mixture was heated in water-bath for $10 \mathrm{~min}$. After two layers are formed, the top layer is measured in volume as the volume of caryophyllene. Eugenol level was calculated using Eq. (5) as:

$\% \mathrm{Eu}=\frac{V_{s}-V_{c}}{V_{s}} \times 100 \%$.

Eu was the percentage of eugenol levels in permeate, $V_{S}$ and $V c$ were the volume of sample and volume of caryophyllene, respectively.

\section{Results and discussions}

\subsection{Characteristics of crude cloves leaf oil}

The characteristics of clove oil was evaluated to know the quality of clove oil before being processed using a membrane. Characterization is conducted by referring to Indonesian National Standard (SNI) 06-2387-2006 standard for clove oil quality parameters. The results of clove oil characterization are presented in Table 2.

Based on Table 2, it can be seen that the specific gravity and total eugenol content is still below the quality standard according to SNI. Clove oil density was $1.014 \mathrm{gr} / \mathrm{mL}$ while the SNI standard must be between 1.025-1.049 gr/mL.
Eugenol content of clove oil based on the analysis was $68 \% \mathrm{v} / \mathrm{v}$ while the standard was at least $78 \% \mathrm{v} / \mathrm{v}$. From the results of this characterization it can be concluded that clove oil from leaves is still below the standards required by SNI, this is probably caused by many other impurities compounds other than eugenol contained in clove oil. The compound components contained in clove oil in this study were analyzed using GCMS, the clove oil component analysis is presented in Table 3.

Based on the results of component analysis using GCMS as shown in Table 3, the main component composing clove oil in this study was eugenol with a composition of $69.51 \%$. This result is almost equal to the result of total eugenol analysis by volumetric method that is obtained result of $68 \%$. Another dominant component is trans-caryophyllene of $25.19 \%$. The composition of caryophyllene in clove oil sample is still above the maximum standard required by SNI. Other components in clove oil are alpha-Cubebene and alpha-Humulene which are compounds commonly found in essential oils especially clove oil [35]. In addition, also found compounds hexadecanoic acid ethanedhiyl ester of $1.58 \%$ which is an ester compound of fatty acid type palmitic acid. This fatty acid is a type of fatty acid commonly found in extracts of vegetable oils, especially coconut oil. Clove oil sample from Semarang, Indonesia still contains many components of impurities. Therefore, cloves leaf oil needs to be treated to increase its eugenol content, so that the price of clove oil could be higher.

Table 2 Characteristics of crude clove oil raw materials

\begin{tabular}{llccc}
\hline No. & \multicolumn{1}{c}{ Parameter } & Unit & Clove oil sample & SNI Standard \\
\hline 1. & Odor and color & - & Typical of cloves and yellow-brownish & Typical of cloves and yellow-brownish \\
2. & Density at $20^{\circ} \mathrm{C}$ & $\mathrm{gr} / \mathrm{mL}$ & 1.014 & $1.025-1.049$ \\
3. & Refractive index $\left(\mathrm{n}_{20}\right)$ & - & 1.530 & $1.528-1.535$ \\
4. & Solubility in EtOH $70 \%$ & - & $1: 2.5$ & $1: 2$ clear \\
5. & Total eugenol concentration & $\%, \mathrm{v} / \mathrm{v}$ & 68 & $\min 78$ \\
6. & $\beta$-caryophyllene & $\%$ & 25.19 & $\max 17$ \\
\hline
\end{tabular}

Table 3 Chemical components in crude cloves leaf oil

\begin{tabular}{|c|c|c|}
\hline No. & Component & $\begin{array}{c}\text { Percentage } \\
(w \mathrm{t} \%)\end{array}$ \\
\hline 1 & Phenol, 2-methoxy-4-(2-propenyl)-(Eugenol) & 69.51 \\
\hline 2 & Alpha-Cubebene & 0.93 \\
\hline 3 & Trans-Caryophyllene & 25.19 \\
\hline 4 & Alpha-Humulene & 2.79 \\
\hline 5 & Hexadecanoic acid, 1-(Hydroxymethyl)-1,2-ethanedhiyl ester & 1.58 \\
\hline Total & & 100 \\
\hline
\end{tabular}




\subsection{Membrane morphology using scanning electron microscope}

SEM characterization was carried out on the fabricated membrane in order to observe the morphological structure of both the surface membrane and cross-section. The information about membrane morphological structure is important because it plays an important role in the properties of selectivity and permeability. $\mathrm{CA}-\mathrm{TiO}_{2}$ hybrid membrane samples with and without crosslinked PVA coating were scanned at 20,000x magnification for surface section and 5,000x magnifications for cross section. The surface morphology and cross-sectional SEM images for the $\mathrm{CA}-\mathrm{TiO}_{2}$ and $\mathrm{CA}-\mathrm{TiO}_{2}$ PVA coated membranes are shown in Fig. 3.

Fig. 3A and 3B show SEM images of membrane surface without and with PVA coating. At this magnification, Fig. 3A clearly reveals the presence of nano-particles and some voids. While, Fig. 3B also shows the presence of nano-particles and the absence of void formation. The nano- $\mathrm{TiO}_{2}$ particles are spread evenly on the both membranes, this could be due to the well mixing process during membrane preparation and the particle loading concentration is appropriate. The over-loading of nano-particle in membrane matrix could be disadvantageous due to the agglomerate formation which decreases the membrane selectivity significantly. Furthermore, by addition of PVA coating on the membrane surface caused the nano-particles are covered by PVA layer and the membrane become smoother, beside the PVA coating remove voids on the membrane surface.

Foremost, by referring Fig. 3.C and D, the addition of crosslinked PVA coating on the CA membrane, the selective layer of the membrane become denser and thicker. As shown in Fig. 3.C, the top layer of the membrane was observed to approximately around $436 \mathrm{~nm}$, while the membrane as shown in Fig. 3.C, the top layer was observed to approximately around $859 \mathrm{~nm}$. This fact is proving that PVA coatings can improve membrane selectivity because the expected of this membrane preparation is solution diffusion separation mechanism on differences
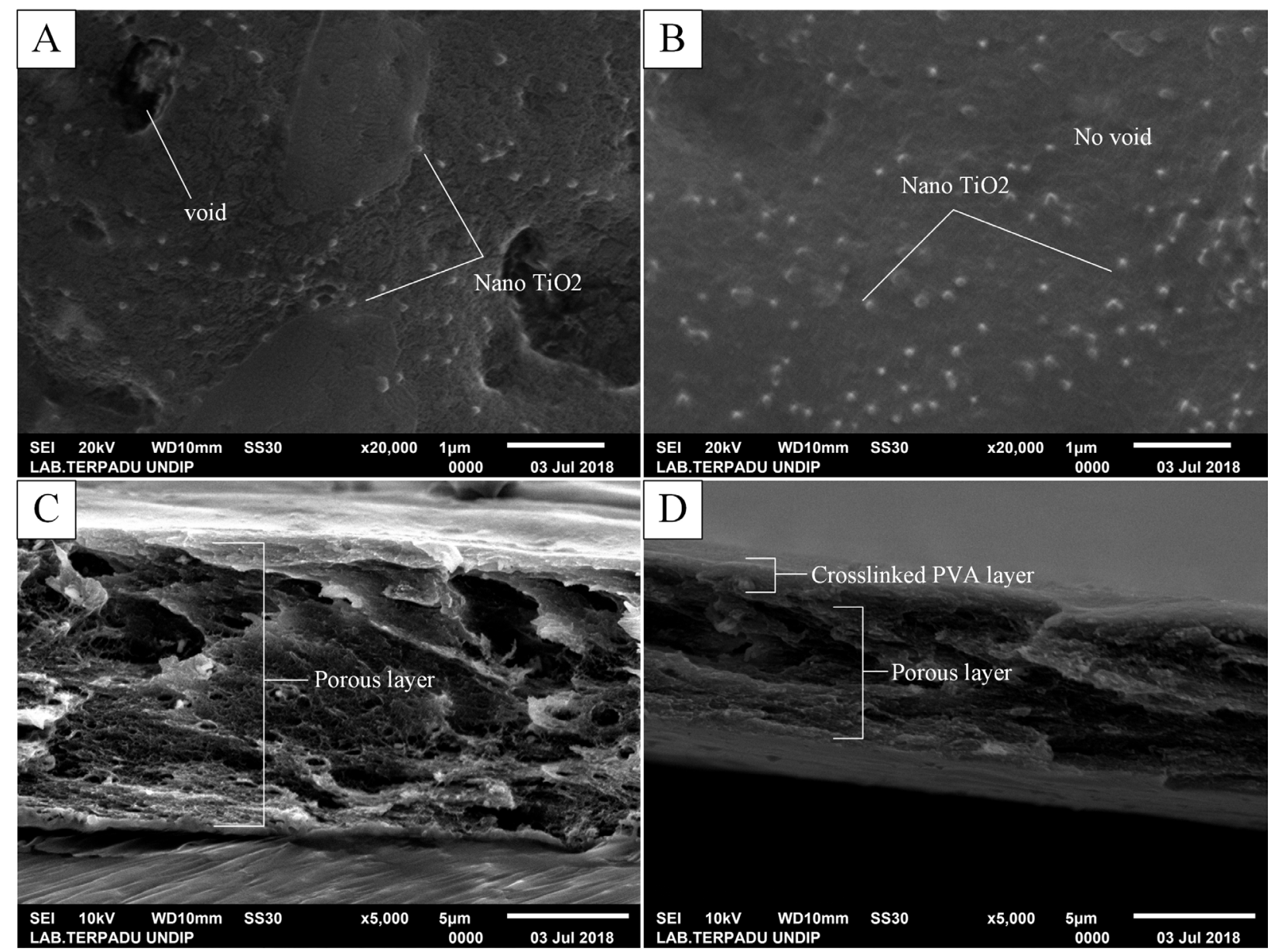

Fig. 3 SEM images of CA-TiO2 membrane surface without coating (A) and with crosslinked PVA coating (B), membrane cross-section without coating (C) and with crosslinked PVA coating (D) 
in the molecular affinity of the membrane and separated molecules. However, the thicker selective layer is not favorable because it will increase the resistance which decreases the permeability.

\subsection{Fourier transform infra-red analysis results}

Characterization using FTIR aims to investigate the functional groups in the membrane and to recognize the changes of functional groups occurring during the membrane modification process. This analysis is important to know the success of the coating process and cross-linking of PVA with glutaraldehyde. FTIR spectra for the various membranes made in this study are presented in Fig. 4.

The FTIR spectra of the CA membrane are characterized by vibrations at $3300-3500 \mathrm{~cm}^{-1}, 2850 \mathrm{~cm}^{-1}$ and $1754 \mathrm{~cm}^{-1}$ are indicating the presence of - $\mathrm{OH}$ groups, stretching of the - $\mathrm{CH}$ group, and the vibration of $\mathrm{C}=\mathrm{O}$ ester groups. Peaks that appear in the wavelength range $1520-1370 \mathrm{~cm}^{-1}$ show the stretching bands of $\mathrm{CH}_{2}$ and $\mathrm{CH}_{3}$. In Fig. 4 shows that the entire spectra of FTIR has -OH group of alcohols characterized by a peak width of 3500-3000 $\mathrm{cm}^{-1}$. Cellulose acetate has an $\mathrm{OH}$ group bonded by a saturated carbon chain, whereas PVA has -OH group in a polymer chain bound by an unsaturated carbon chain $\left(\mathrm{sp}^{2}\right)$ in the edge.

Changes of functional groups in the membrane can be marked by missing or emerging new peak, shifting, or changes in intensity. The wide peak which is representing the $-\mathrm{OH}$ group on the $\mathrm{CA}-\mathrm{TiO}_{2}$ membrane is wider than that of the CA membrane. This shows that the addition of $\mathrm{TiO}_{2}$ can increase the intensity of the $-\mathrm{OH}$ vibration.
This phenomenon occurs because $\mathrm{TiO}_{2}$ is a super-hydrophilic particle and has a great affinity for water molecules. Therefore, the addition of $\mathrm{TiO}_{2}$ to the CA membrane can be said to increase the hydrophilicity of the membrane.

FTIR spectra for PVA (spectra E) show that the PVA polymer used in this research was partially hydrolyzed PVA, since the vibration of the hydroxyl group $(-\mathrm{OH})$ occurs from wavelengths of 2923 to $3600 \mathrm{~cm}^{-1}$. The peak indicates the vibration of the $\mathrm{OH}$ group possessed by the alcohol and the carboxylic acid. Referring to the FTIR C and D spectra of the CA membrane coated with PVA, there appears to be a widening of peak from 3300 to $3500 \mathrm{~cm}^{-1}$ becomes 3000 to $3500 \mathrm{~cm}^{-1}$. This occurs because of the addition of - $\mathrm{OH}$ groups derived from alcohol chains and carboxylates to PVA compounds.

In the FTIR spectra for CA membranes coated with PVA and crosslinked PVA also show the greater the $-\mathrm{OH}$ vibration value compared to the CA membrane, this is due to the addition of the -OH group from PVA. Peak at 2870 and $2920 \mathrm{~cm}^{-1}$ appear on the membrane $\mathrm{CA}, \mathrm{CA}-\mathrm{TiO}_{2}$, and $\mathrm{CA}-\mathrm{TiO}_{2} / \mathrm{PVA}$ refers to the $\mathrm{OH}$ group attached to the unsaturated and aldehyde chains. Crosslinking between glutaraldehyde and -OH groups in PVA compounds is characterized by peak disappearance at $2870 \mathrm{~cm}^{-1}$ wavelength and reduced band intensity in the $3500-3000 \mathrm{~cm}^{-1}$ range [36]. This occurs as a result of the reaction between PVA and glutaraldehyde, where the $\mathrm{OH}$ group of PVA reacts with $\mathrm{OH}$ of glutaraldehyde to form the acetal bridge as shown in Fig. 5.

In addition, sharpening of the bands in the range 1150$1050 \mathrm{~cm}^{-1}$ shows the emergence of the $\mathrm{C}-\mathrm{O}-\mathrm{C}$ ether group

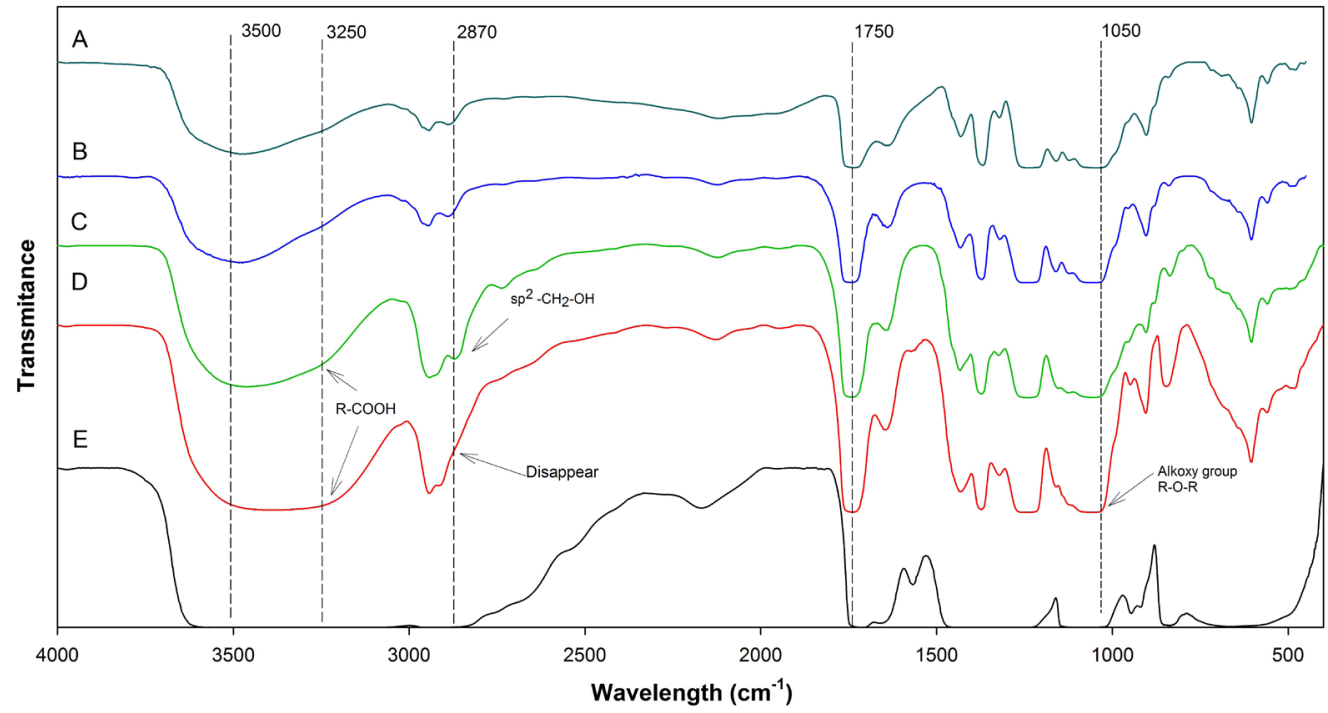

Fig. 4 FTIR spectra of (A) CA membrane, (B) CA-TiO ${ }_{2}$ membrane, (C) CA-TiO $/ 2$ PVA membrane, (D) $\mathrm{CA}-\mathrm{TiO}_{2} / \mathrm{PVA}$ crosslinked membrane, and (E) PVA polymer 


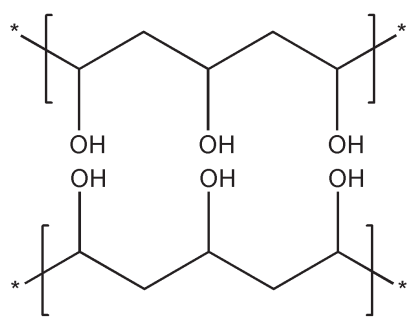

Poly(vinyl alcohol)

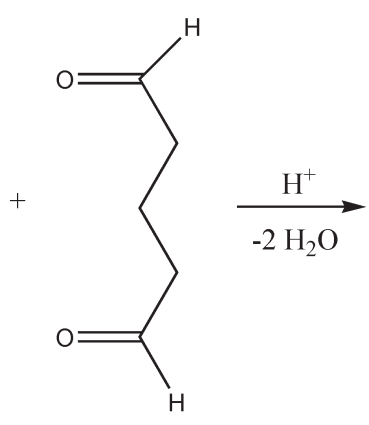

Glutaraldehyde

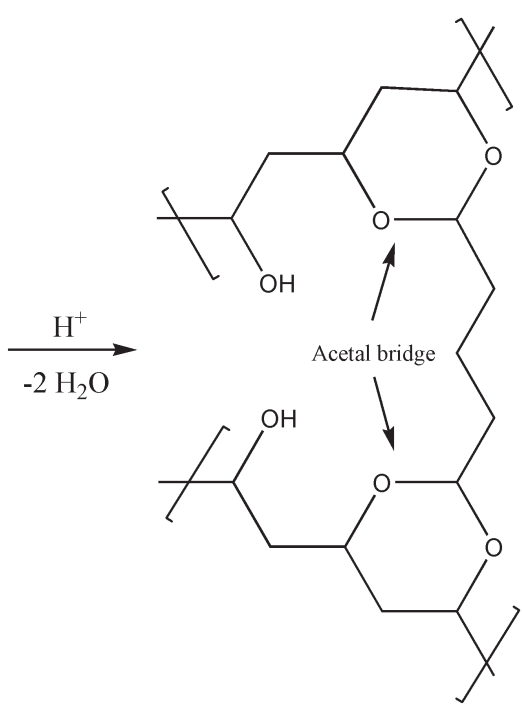

Cross-linked PVA

Fig. 5 The reaction of poly vinyl alcohol with glutaraldehyde

as a crosslinking product between aldehyde groups and alcohol groups. The structural features of FTIR from CA, $\mathrm{CA}-\mathrm{TiO}_{2}, \mathrm{CA}-\mathrm{TiO}_{2} / \mathrm{PVA}$, and $\mathrm{CA}-\mathrm{TiO}_{2} / \mathrm{PVA}$ crosslinked membrane indicate composite membrane with a crosslinked PVA layer has been successfully constructed. The series of modifications seen from the functional groups formed capable of producing membranes with high hydrophilicity as well as durability to be justified by other characterization and filtration tests.

\subsection{X-Ray Diffraction of fabricated membrane}

XRD membrane diffraction is useful for determining the crystallinity phase of the membrane, but it can also be used to determine the presence of inorganic particles added to the membrane as filler. This characterization is particularly needed in the manufacture of hybrid membranes involving nano-particles as fillers. This is due to the process of membranes fabrication via NIPS method involved deionized water bath for coagulation process (separation process). This stages becomes critical because nanoparticles are likely to escape from the polymer matrix. To confirm the presence of nano $\mathrm{TiO}_{2}$ particles in polymer matrix, an XRD analysis were performed. The XRD spectra for $\mathrm{CA}$ and $\mathrm{CA}-\mathrm{TiO}_{2}$ membranes are shown in Fig. 6.

The XRD spectra for the CA membrane as shown in Fig. 6 appears to be irregularly peak and spread evenly across all $2 \theta$ positions, indicating the CA membrane is in the amorphous phase. In contrast to the XRD spectra for $\mathrm{TiO}_{2}$ particles in Fig. 6 in the form of sharp and high peaks indicating the nanoparticles of $\mathrm{TiO}_{2}$ are in the crystalline phase. Spectra $\mathrm{TiO}_{2}$ has a distinctive peak that indicates the presence of $\mathrm{TiO}_{2}$ that is sharp peak at position $2 \theta$ of $27.43^{\circ}$, $36.09^{\circ}, 54.31^{\circ}$, and $69.01^{\circ}$. For the XRD spectra of the $1 \mathrm{wt} \%$ $\mathrm{CA}-\mathrm{TiO}_{2}$ membrane shown in Fig. 6, amorphous peaks are evenly distributed along the $2 \theta$ position, but there is a fairly sharp peak at position $27.66^{\circ}, 36.33^{\circ}, 44.55^{\circ}$, and $54.58^{\circ}$. The peaks are analogous to the unique peak positions of $\mathrm{TiO}_{2}$, indicating that the $\mathrm{TiO}_{2}$ particles are present in the CA membrane matrix. This method has been applied by earlier researchers to ascertain the presence of inorganic particles in the polymer membrane matrix $[32,37]$.

\subsection{MWCO, porosity, and average pore radius of prepared membranes}

The parameters of MWCO, porosity, and average pore radius are important to be analyzed because these parameters are closely related to membrane performance. MWCO (Molecular Weight Cut-off) is a value that shows the molecular weight of a solute that can be rejected by the membrane up to $90 \%$. These dissolved substances are usually polymers such as dextran, albumin, and PEG. the MWCO's value of each membrane was obtained by analyzing the PEG content in the permeate after passing the each membrane barriers. Different solute molecular weight resulted in different rejection efficiency. The PEG rejections of each membrane were plotted againt PEG's MW. MWCO's values were obtained by intersecting the PEG rejection graph at $90 \%$ rejection. Meanwhile, the porosity is the void fraction in the membrane to the total volume of the membrane. And the average pore radius is the average 

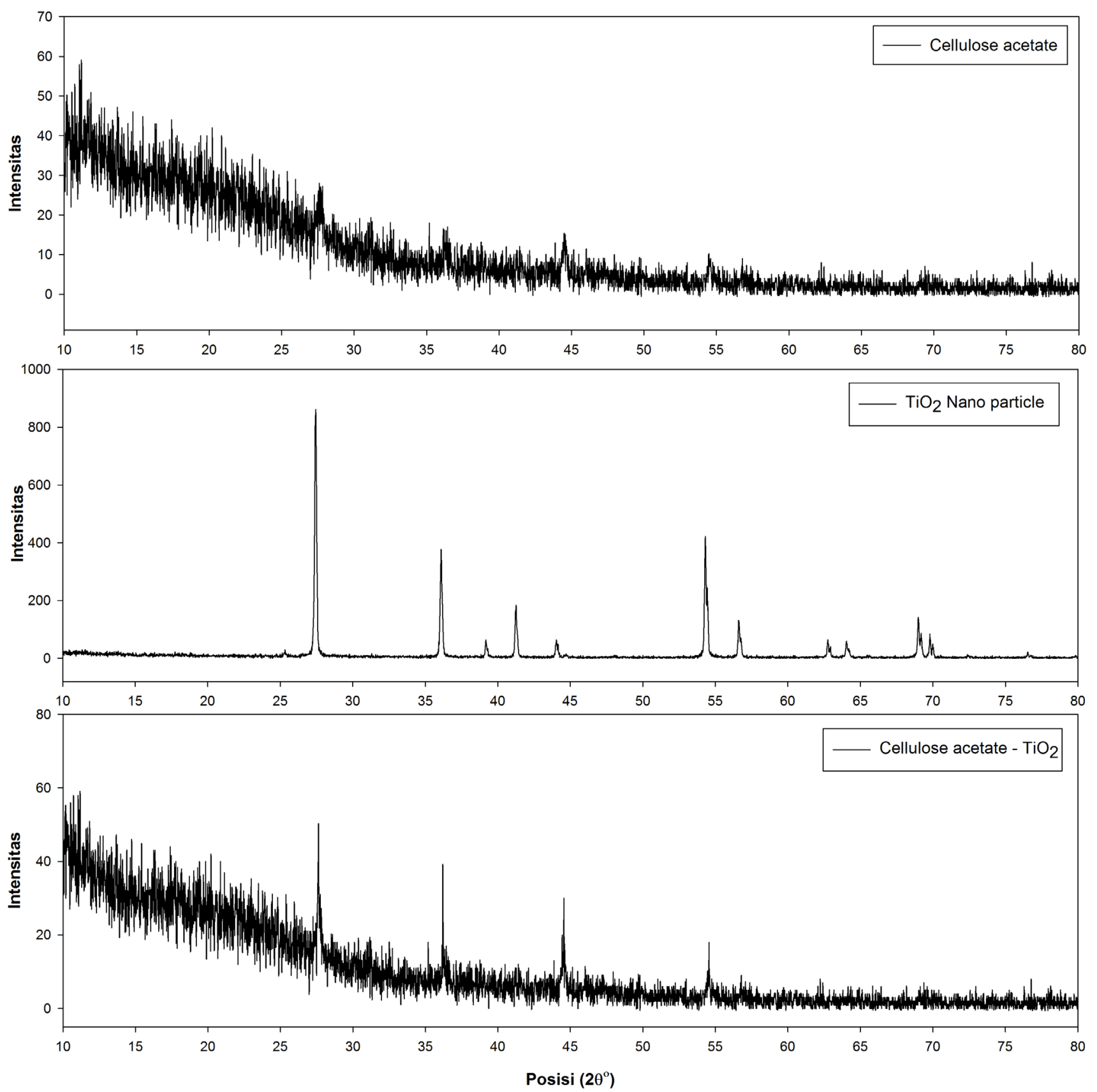

Fig. 6 XRD spectra (a) CA membrane, (b) $\mathrm{TiO}_{2}$ particle powder, and (c) CA-TiO, hybrid membrane $1.0 \%$

size of membrane pores whose value has a correlation with MWCO, indirectly MWCO represents the pore size of the membrane. The results of MWCO characterization, porosity, and membrane pore radius are presented in Table 4.

Based on Table 4, a membrane with a polymer concentration of 14 and $16 \%$ is not capable in rejecting the PEG 6000 up to $90 \%$, so its MWCO value is more than $6000 \mathrm{Da}$ and its average pore size is more than $2.13 \mathrm{~nm}$. The higher concentration of CA in dope solution will result in a smaller membrane with $\mathrm{MWCO}$ value. At CA concentrations of $18 \%$ and $20 \%$ their MWCO values were 5674 and $2062 \mathrm{Da}$, respectively. With the higher concentration of polymer in dope solution, the distance between polymer molecules is getting closer so that membrane with smaller pore size will be produced. With the addition of nano-particles $\mathrm{TiO}_{2}$, the MWCO membrane value did not change significantly, which is about 5600s Da. Moreover, in general, the higher the concentration of $\mathrm{TiO}_{2}$ in the polymer matrix the smaller the MWCO value. The presence of nano-particles in the membrane divides the large gap into 
Table 4 MWCO value, porosity, and average pore radius of the prepared membranes

\begin{tabular}{lccc}
\hline Membranes & $\begin{array}{c}\text { MWCO } \\
\text { (Da) }\end{array}$ & Porosity & $\begin{array}{c}\text { Pore radius } \\
\text { (nm) }\end{array}$ \\
\hline M1 & $>6000$ & 0.6454 & $>2.13$ \\
M2 & $>6000$ & 0.5211 & $>2.13$ \\
M3 & 5674 & 0.4793 & 2.06 \\
M4 & 2062 & 0.3513 & 1.17 \\
M5 & 5680 & 0.4631 & 2.06 \\
M6 & 5667 & 0.4691 & 2.06 \\
M7 & 5657 & 0.4686 & 2.06 \\
M8 & 5642 & 0.4497 & 2.06 \\
M9 & 5632 & 0.4409 & 2.05 \\
M10 & 5588 & 0.4296 & 2.05 \\
M11 & 5000 & 0.4137 & 1.92 \\
M12 & 2875 & 0.4017 & 1.41 \\
\hline
\end{tabular}

small crevices without forming a dead-end void and resulting in a narrowing of the membrane pores. However, results in this study of membrane pore sizes tend to be fixed, this may be due to changes caused by the addition of $\mathrm{TiO}_{2}$ is very small because the concentration of nano-particles is relatively low. While increasing the concentration of PVA in the coating material significantly influences the MWCO value. By increasing the concentration of PVA up to $5 \%$ can reduce the value of MWCO from 5632 to $2875 \mathrm{Da}$ or with the size of pore radius $1.41 \mathrm{~nm}$. The MWCO parameters and membrane pore radius have contributed in providing selective properties of the membrane. Even though the porosity is usually increased the membrane permeability. A membrane is expected to have dense layers that are dense and as thin as possible but have a highly porous intermediate portion, so membrane selectivity can be maximized without decreasing membrane permeability [38]. Even in this study PVA coating was unable to form nonpore dense layer as expected, the pore-size and the porosity of the membrane could be reduced.

\subsection{Membrane swelling degree}

The phenomenon of swelling on the membrane is a very avoidable thing, because membrane swelling will change characteristic so that membrane performance. Most striking is the membrane that swelling the membrane pores will widen so that the separation efficiency will decrease drastically. In clove oil purification studies using this membrane it is necessary to test swelling observations, since most polymers in contact with eugenol will swell, or weaken, or crumble. Fig. 7 is a membrane volume ratio profile after having initial swelling and volume as a function of time.

According to Fig. 7, the membrane volume change profile after immersion in eugenol indicates a significant increase in volume in the first hour, and then begins to show steady state. At the beginning of the immersion time, eugenol molecules enter the pores of the membrane and push the polymer molecules further apart. In eugenol compounds, there are hydrophilic groups and hydrophobic groups that can dissolve some types of polymers. However, against cellulose acetate, eugenol is not able to dissolve but is able to pull CA polymer molecules far apart [39]. In addition to the immersion time there is no significant volume change this is due to the polymer molecules that are unable to swell. This happens because it has reached the equilibrium state, ie

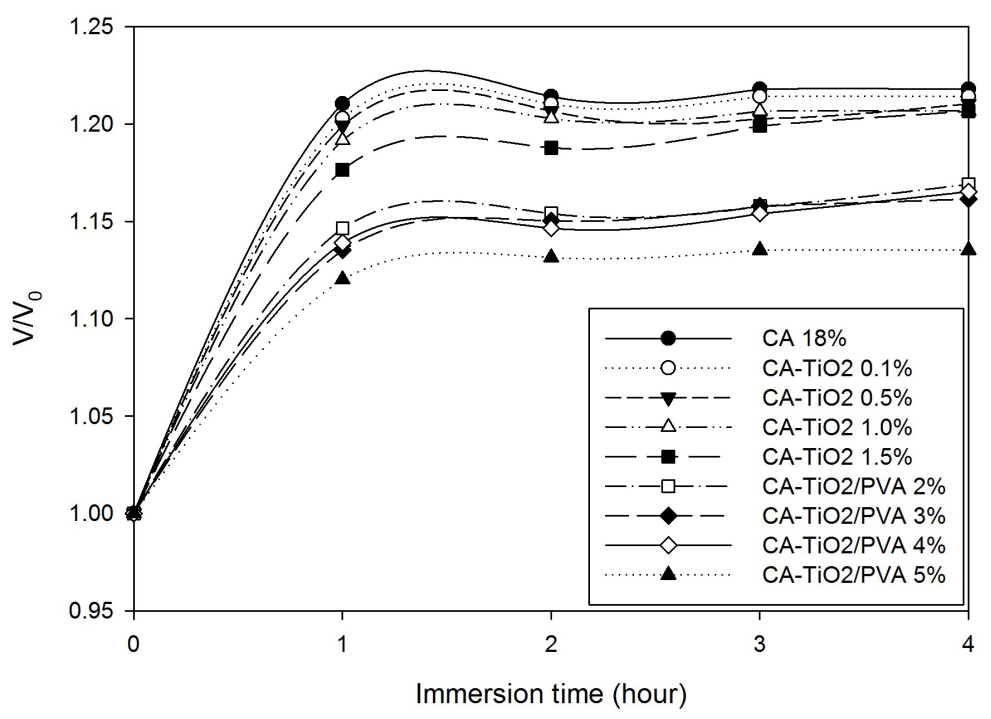

Fig. 7 Profile of membrane volume ratio after swelling as a function of time 
the force of attraction between molecules by eugenol in the polymer matrix is equal to the attraction between molecules by eugenol outside the polymer matrix.

The average swelling degree for each of the membranes is presented in Fig. 8 to obtain the effect information from the nano- $\mathrm{TiO}_{2}$ incorporation and coating using crosslinked PVA. The higher concentrations of CA polymers in dope solution appear to decrease the degree of membrane swelling significantly. This occurs because the higher the concentration of CA the polymer molecules will be denser per unit volume, so that the movement of the polymer molecules is limited and result in small changes in the volume of membrane. However, attempts to suppress membrane swelling by increasing polymer concentrations are an imprecise choice because the higher polymer concentration the consequence is the lower of membrane permeability (decreased productivity).

The degree of swelling also decreases with the increasing concentration of nanoparticles filled into the CA polymer. The addition of nano-particles $\mathrm{TiO}_{2}$ to a concentration of $1.5 \%$ can decrease the degree of swelling of membranes from 1.22 to 1.19. This occurs because the $\mathrm{TiO}_{2}$ particles limit the movement of polymer molecules so that the penetration of eugenol molecules can be reduced. The most significant decrease in swelling degree is the addition of a crosslinked PVA layer using glutaraldehyde. The decrease of swelling with the addition of a $5 \%$ PVA layer can decrease the degree of swelling from 1.22 to 1.13 . This effect is caused by a very hydrophilic PVA layer as the FTIR analysis results show that the $-\mathrm{OH}$ group vibration band is very wide. It is this property that causes the interaction between PVA and eugenol weak so that the penetration of eugenol molecules into the polymer matrix is not as large on the membrane without PVA coating. In addition, the coated PVAs on the membrane surface have been crosslinked using glutaraldehyde, forming cross-linked polymers to form a more robust polymer network. This cross-linking modification is expected to be able to maintain the membrane characteristics during clove oil purification process, thus the separation properties don't change significantly.

\subsection{Water contact angle measurement results}

Measurement of water contact angles on membrane surfaces has become a commonly used method of membrane characterization. The membrane contact angle contact information is useful in determining the surface tension of the membrane. Surface tension on the membrane is related to membrane hydrophilicity and relative roughness of the membrane. The value of the contact angle is obtained by dripping the ion free water on the membrane surface and measuring the droplet angle. The results of measurements of water contact angles on the surface of the membrane that have been prepared are presented in Table 5.

Based on the data of the angle of contact shown in Table 5, the entire membrane indicates a contact angle value of less than $90^{\circ}$, indicating that the membrane surface is essentially hydrophilic. On increasing the CA concentration, the contact angle value tends to be constant, indicating that the contact surface angle of the membrane is not affected by the polymer concentration. Addition of $0.1 \% \mathrm{TiO}_{2}$ particle nano turned out to increase the contact angle from $40.33^{\circ}$ to $42.33^{\circ}$. This is likely due to the addition of nano-particles

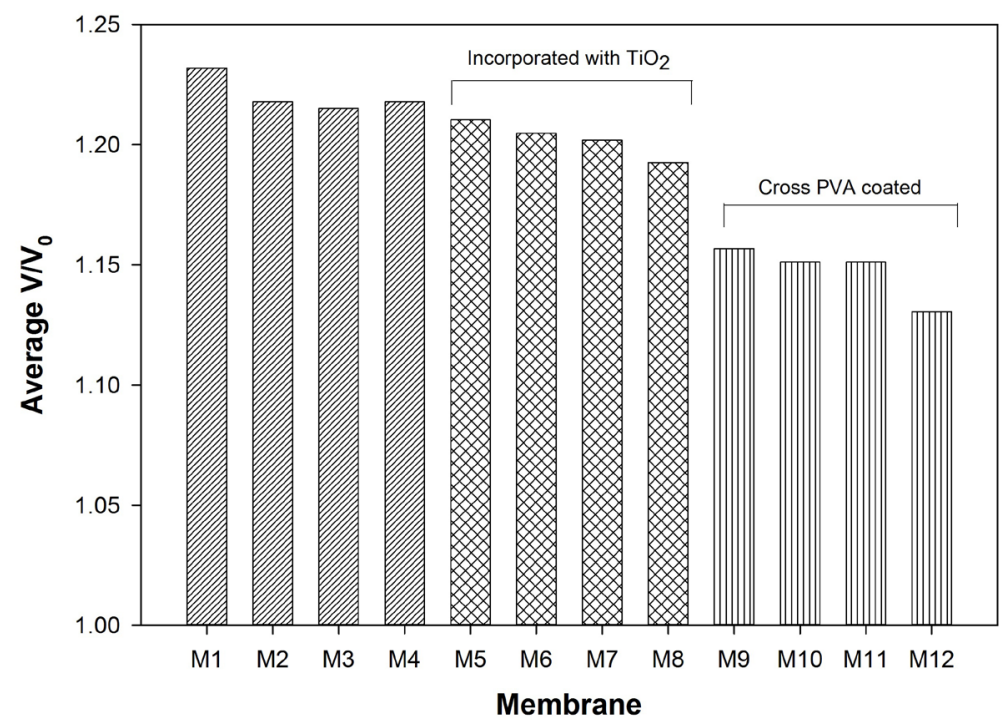

Fig. 8 Membrane swelling degrees of various types of fabricated membranes 
Table 5 Measurement results of water contact angles on the surface of the various membranes that have been made

\begin{tabular}{lcc}
\hline Membranes & Dope composition & Contact angle $\left(^{\circ}\right)$ \\
\hline M1 & $\mathrm{CA} 14 \%$ & 41.00 \\
M2 & $\mathrm{CA} 16 \%$ & 40.33 \\
M3 & $\mathrm{CA} 18 \%$ & 40.33 \\
M4 & $\mathrm{CA} 20 \%$ & 41.33 \\
M5 & $\mathrm{CA} 18 \%, \mathrm{TiO}_{2} 0.1 \%$ & 42.33 \\
M6 & $\mathrm{CA} 18 \%, \mathrm{TiO}_{2} 0.5 \%$ & 30.61 \\
M7 & $\mathrm{CA} 18 \%, \mathrm{TiO}_{2} 1.0 \%$ & 32.67 \\
M8 & $\mathrm{CA} 18 \%, \mathrm{TiO}_{2} 1.5 \%$ & 34.33 \\
M9 & $\mathrm{CA}-\mathrm{TiO}_{2} 0.5 \% / \mathrm{PVA} 2 \%$ & 10.25 \\
M10 & $\mathrm{CA}-\mathrm{TiO}_{2} 0.5 \% / \mathrm{PVA} 3 \%$ & Spreading \\
M11 & $\mathrm{CA}-\mathrm{TiO}_{2} 0.5 \% /$ PVA $4 \%$ & Spreading \\
M12 & $\mathrm{CA}_{2}-\mathrm{TiO}_{2} 0.5 \% /$ PVA $5 \%$ & Spreading \\
\hline
\end{tabular}

to the polymer matrix causing the membrane surface to become rough. However, in the addition of nano-particles $\mathrm{TiO}_{2}$ with a higher concentration of $0.5 \%$ decreased contact angle value, this is due to the possible effect of increased hydrophilicity of membrane surface by $\mathrm{TiO}_{2}$ particles [40]. The $\mathrm{TiO}_{2}$ particles based on previous studies are hydrophilic particles and can increase membrane hydrophilicity. This statement is reinforced by FTIR analysis results where the $-\mathrm{OH}$ vibration band on the $\mathrm{CA}-\mathrm{TiO}_{2}$ membrane is larger than the CA membrane. However, in the addition of nano-particles with higher concentrations of $1.0 \%$ and $1.5 \%$ of contact angle values rise again. This is most likely due to roughness effects due to the more dominant addition of nanoparticles compared with an increase in membrane hydrophilicity. So it can be concluded that the addition of nanoparticle membrane $\mathrm{TiO}_{2}$ gives two contradictory effects, which increase the hydrophilicity and increase the roughness of the membrane surface. In this study it was found that concentrations with increased effects of hydrophilicity were more dominant at $0.5 \%$ concentrations.

The addition of a PVA layer on the surface of the $\mathrm{CA}-\mathrm{TiO}_{2}$ membrane significantly decreases the contact angle. With a $2 \%$ PVA coating capable of decreasing the contact angle from $30.61^{\circ}$ to $10.25^{\circ}$. Especially in the addition of PVA coating with concentrations of $3 \%$, $4 \%$, and $5 \%$ respectively can decrease the contact angle to be spreading. This shows the membrane surface to be very hydrophilic, since the surface contact angle was not measurable (spreading). The membrane surface which is too hydrophilic in this work is less preferred because the compound to be purified is hydrophobic. If the membrane surface is too hydrophilic, the clove oil permeation will decrease. Membrane hydrophilicity significantly influences the separation properties of membranes [41] in this study because the compounds to be separated have different affinities. Therefore the addition of PVA as a coating material is expected to increase the efficiency of the separation of eugenol/caryophyllene.

\subsection{Separation experiment for crude clove oil using prepared membrane \\ 3.8.1 Permeate flux}

The effect of the variables on the process of preparing the hybrid membrane CA on the permeate flux in clove oil purification was studied in this study. Fig. 9 is a bar chart showing the total value of cumulative flux for each of the membranes created.

The CA polymer concentrations, $\mathrm{TiO}_{2}$ concentrations and PVA concentrations are highly influential process variables on membrane performance, especially flux. Based on the experimental results shown in Fig. 9, generally the higher the CA concentration is resulting in lower total flux. The highest total flux value was shown by the M1 membrane witha $14 \mathrm{wt} \%$ CA concentrationat $2.56 \mathrm{~L}^{\mathrm{O}} \times \mathrm{m}^{-2} \times \mathrm{h}^{-1} \times \mathrm{bar}^{-1}$ then decreaseddrastically to $0.61 \mathrm{~L} \times \mathrm{m}^{-2} \times \mathrm{h}^{-1} \times$ bar $^{-1}$ withincreasing CA concentration to $16 \%$. While the increase in CA concentration to $18 \%$ and $20 \%$, the total reduction of total flux is relatively smallieto 0.54 and $0.2 \mathrm{~L} \times \mathrm{m}^{-2} \times \mathrm{h}^{-1} \times \mathrm{bar}^{-1}$. Thisphenomenon occurs because the membrane with a concentration of CA $14 \%$ swells with the largest volume ratio compared to the concentration of $16 \%, 18 \%$, and $20 \%$. This swelling causes the membrane pore to widen so that the total flux rate increases. In the addition of $\mathrm{TiO}_{2}$ nano-filler, as seen in Fig. 9 the higher concentration of nano $\mathrm{TiO}_{2}$ the higher total flux is obtained. This is due to the addition of nanoparticles during membrane fabrication prevents the formation of clogged pores, other than that the nano-particles also keep the membrane from the compaction caused by pressure driven over the membrane [42]. Membrane coating using PVA gives an effect inversely with the total flux value, the higher of PVA concentration used as the coating agent the flux value decreases significantly. At PVA concentrations of $2 \%, 3 \%, 4 \%$, and $5 \%$ the total flux values were $0.60,0.48$, 0.35 , and $0.19 \mathrm{~L} \times \mathrm{m}^{-2} \times \mathrm{h}^{-1} \times \mathrm{bar}^{-1}$, respectively. The higher the PVA concentration as a coating material the thicker the layer is formed; this will increase membrane hydrophilicity (as shown in Table 5) which also increases increase the resistance for eugenol to pass through the membrane since eugenol itself is considered as hydrophobic substance, this is in accordance with the results shown in Fig. 9. 


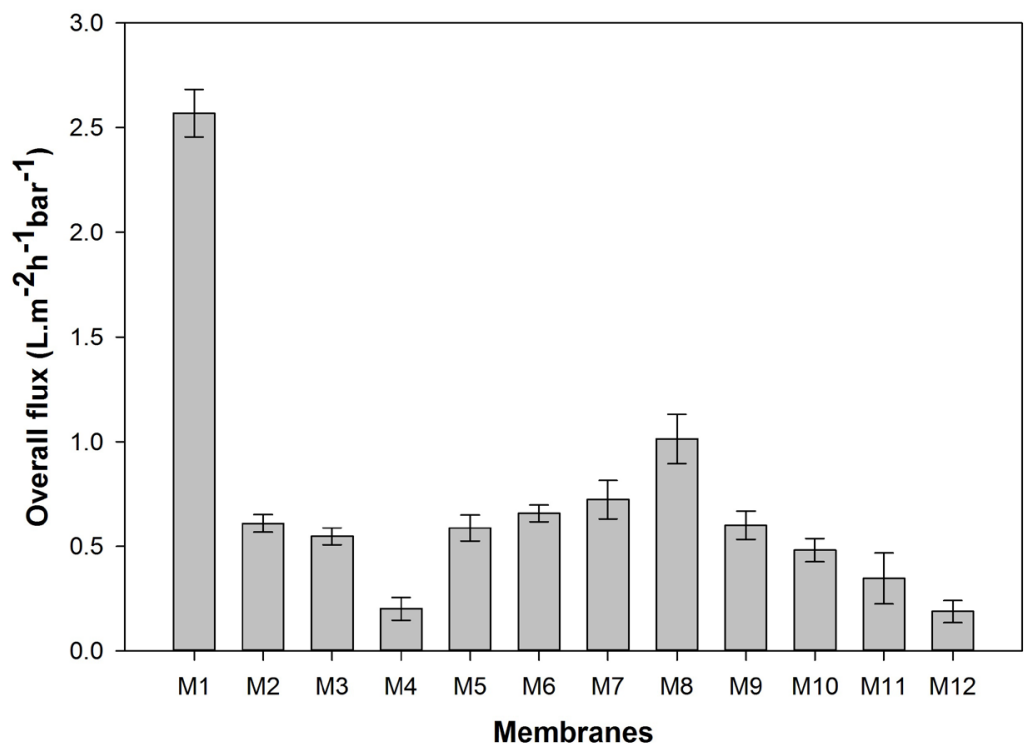

Fig. 9 The total stem diagram of the clove oil permeate flux on the various membranes

\subsubsection{Eugenol content in permeates}

Another parameter that also determines membrane performance is the selectivity or membrane separation properties. In this study, membrane selectivity was determined by the capability of the membrane to reject impurities in clove oil. The higher the concentration of eugenol in permeate it can be said that the membrane has higher rejection efficiency. The results of eugenol content measurement for each permeate obtained from fabricated membranes are shown in Fig. 10.

Fig. 10 shows the variation of eugenol concentration in permeate, on the CA polymer concentration variable, the higher the CA concentration, the higher the eugenol content in permeate. The concentration of eugenol on permeate membranes M1, M2, M3, and M4 were $65 \%, 67.5 \%$, $70 \%$, and $87.5 \%$, respectively. The concentration of eugenol on permeates M1, M2, and M3 are still the same as feeding eugenol concentration, the variation of these results may comes from deviation of the experiment. It shows that the membrane with CA concentration $14 \mathrm{wt} \%$ and $16 \mathrm{wt} \%$ did not occur eugenol separation. However, the addition of nano- $\mathrm{TiO}_{2}$ at concentration $0.1 \mathrm{wt} \%$ on the dope solution, the eugenol levels more higher than eugenol levels without nano filler $\mathrm{TiO}_{2}$, that is $77.5 \%$, respectively. The addition of nano- $\mathrm{TiO}_{2}$ also contributes to the increase of membrane hydrophilicity, in addition to the presence of inorganic particles also provides molecular sieving separation mechanism. However, the higher the concentration of nano $\mathrm{TiO}_{2}$ decreased the eugenol content in permeate. This phenomenon is probably caused by the formation of a micro gap (void) on the surface of the nano-particles larger than the

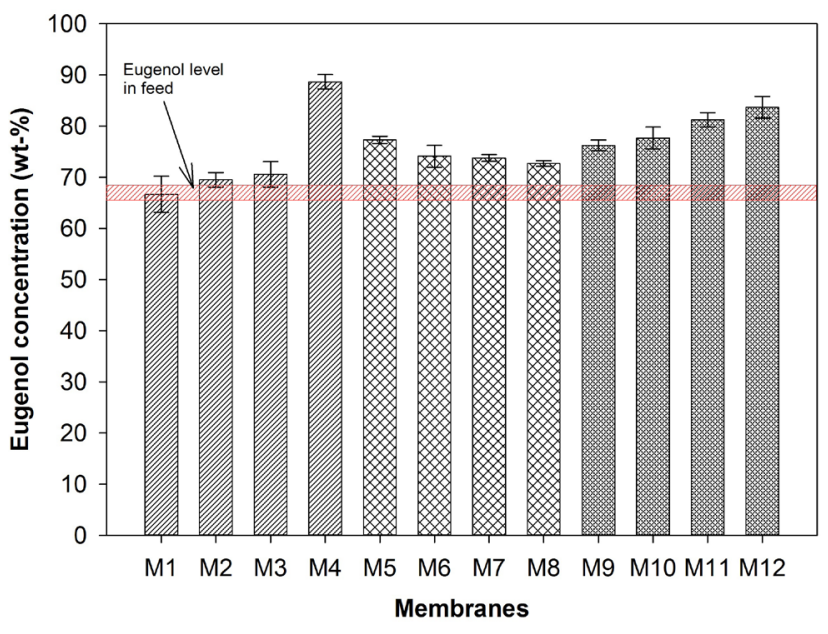

Fig. 10 Eugenol concentration in permeates, red mark is eugenol content of feed

pores of the membrane. This gap is formed due to the de-attachment of polymers on the surface of nanoparticles, one of which is the form of nanoparticles inserted into the membrane. The shape of filler is more closer with the spherical of the polymer attachment is much better. The Nano-particles of $\mathrm{TiO}_{2}$ used in this study are cylindrical in lengths of $350 \mathrm{~nm}$ and $20 \mathrm{~nm}$ diameter. Similar phenomena were also encountered by previous researchers where gaps around the nanoparticles formed that decreased the rejection efficiency [42]. The gap problems can be solved by providing coating materials, in this study PVA is used as a coating material. The higher the PVA concentrations, the eugenol concentration in permeate increases this is due to the interaction between eugenol with PVA and caryophyllene with PVA. The PVA layer is highly hydrophilic and eugenol slightly 
hydrophilic while the caryophyllene is highly hydrophobic. The significant difference in charge between the PVA layer and the caryophyllene molecule causes more and more rejected caryophyllene molecules. However, the eugenol concentration obtained on the M12 membrane is still lower when compared to the permeate produced on the CA membrane concentration of $20 \%$, because the MWCO value of the membrane with a concentration of $20 \%$ is still smaller than the coated CA membrane PVA $5 \%$. Based on the results of this study it can be concluded that the separation of eugenol and caryophyllene could not be performed using membranes with MWCO values above $6000 \mathrm{Da}$, and the purity of eugenol obtained will be above $85 \%$ when using membranes with MWCO values below $2500 \mathrm{Da}$.

The separation efficiency of eugenol towards caryophyllene is mainly affected by CA concentration in dope solution and then hydrophilicity of the membrane. Statistically, the variation of eugenol content in permeates may come from experimental deviation and separation properties. Repetition of the experiments were carried out to avoid errors due to variations in experimental data. The average standard errors of eugenol concentration in permeate is $1.6 \%$. Based on standard error calculation, the variation of eugenol contents of permeate M1, M2, M3, and M8 come from experimental errors, while the enhancement of eugenol content in permeate M4, M5, M6, M7, M9, M10, M11, and M12 were atributed by the separation properties of the membranes.

\subsection{Composition of permeate}

The experimental result using the optimum dope solution composition obtained by permeate flux value is $0.49 \mathrm{~L} \times \mathrm{m}^{-2} \times \mathrm{h}^{-1} \times \mathrm{bar}^{-1}$ and theeugenolconcentrationobtained is $74.5 \%$. The analysis results using GCMS shown in Table 6 also shows similar results.

In Table 6, it can be seen that the concentration of eugenol in clove oil is $74.25 \mathrm{wt} \%$, this result also confirms the value obtained by gravimetric method that is $74.5 \mathrm{wt} \%$. Moreover, in the permeate component there is a hexane compound not found in the GCMS analysis of clove oil feed, it indicates that permeate still contains small residual solvent. There is also an alpha-copaene compound which is an isomer of alpha-cubebene with the formula $\mathrm{C}_{15} \mathrm{H}_{24}$ molecule. Because of the identical mass spectra between alpha-copaene and alpha-cubebene so that these compounds are difficult to identify using GCMS so that in the GCMS analysis, alpha-cubebene is sometimes identified as alpha-copaene. The composition of trans-caryophyllene compounds also decreased from $25 \%$ to $22 \%$, although the concentration of
Table 6 Chemical composition of clove oil as permeate

\begin{tabular}{lcc}
\hline No. & Chemical component & Percentage (wt\%) \\
\hline 1 & Hexane & 0.49 \\
2 & Eugenol & 74.24 \\
3 & Alpha-Copaene & 0.8 \\
4 & Trans-Caryophyllene & 22.06 \\
5 & alpha-Humulene & 2.41 \\
\hline Total & & $\mathbf{1 0 0}$ \\
\hline
\end{tabular}

caryophyllene was still above the maximum limit required by SNI standard [33]. In the permeate composition analysis, no esters of hexadecanoic acid are found, indicating that the fatty acid compound is rejected by the membrane because it has very small hydrophilicity and an elongated and large molecular shape. This phenomenon indicated that this compound is excluded in term of both size and charge.

\section{Conclusion}

Preparation and characterization of $\mathrm{TiO}_{2}$ cellulose acetate hybrid membrane with PVL crosslinked coating has been successfully established. The SEM results show the membrane formed as an asymmetric membrane with a spongelike porous layer structure. FTIR characterization proves that the addition of nanoparticles significantly increases membrane hydrophilicity as well as the PVA crosslinking process with glutaraldehyde successfully performed. The XRD spectra indicate that the membrane is made in the armor phase and appears sharply peak at a position analogous to the $\mathrm{TiO}_{2}$ nano peak. The addition of nanoparticle $\mathrm{TiO}_{2}$ and membrane surface coating using PVA significantly decreased the water contact angle, but the addition of $\mathrm{TiO}_{2}$ with higher concentrations indicated an increase in contact angle due to increased roughness of the membrane surface relative. The highest permeate flux was obtained on the membrane with a $14 \mathrm{wt} \% \mathrm{CA}$ concentration of $2.56 \mathrm{~L} \times \mathrm{m}^{-2} \times \mathrm{h}^{-1} \times \mathrm{bar}^{-1}$ and the lowest flux obtained on the CA membrane by PVA coating of $5 \%$ concentration of $1.88 \mathrm{~L} \times \mathrm{m}^{-2} \times \mathrm{h}^{-1} \times \mathrm{bar}^{-1}$. Thehighesteugenolconcentrationin permeate was obtained using CA $20 \mathrm{wt} \%$ concentration membrane of $87.5 \%$ and the lowest eugenol concentration was obtained using membrane with concentration of CA $14 \%$ that is equal to $65 \%$. In general, CA membrane has potential to be used for clove oil purification. The high separation effciency could be acheived if the membrane has non-pore dense layer. The PVA coating in this study was unable to provide a non-pore dense layer however it was able to significantly increase the hydrophilicity of the membrane, therefore separation efficiency could be enhanced. 


\section{Acknowledgement}

We gratefully acknowledge the facility support from the Waste management laboratory of Chemical Engineering

\section{References}

[1] Gilmer, C. M., Bowden. N. B. "Highly Cross-Linked Epoxy Nanofiltration Membranes for the Separation of Organic Chemicals and Fish Oil Ethyl Esters", ACS Applied Material Interfaces, 8(36), pp. 24104-24111, 2016. https://doi.org/10.1021/acsami.6b07749

[2] Ravanchi, M. T., Kaghazchi, T., Kargari., A. "Application of membrane separation processes in petrochemical industry: a review", Desalination, 235(1-3), pp. 199-244, 2009. https://doi.org/10.1016/j.desal.2007.10.042

[3] Donelian, A., de Oliveira, P. F., Rodrigues, A. E., Mata, V. G., Machado, R. A. F. "Performance of reverse osmosis and nanofiltration membranes in the fractionation and retention of patchouli essential oil", The Journal of Supercritical Fluids, 107, pp. 639-648, 2016.

https://doi.org/10.1016/j.supflu.2015.07.026

[4] Spricigo, C. B., Bolzan, A., Machado, R. A. F., Carlson, L. H. C., Petrus, J. C. C. "Separation of nutmeg essential oil and dense CO2 with a cellulose acetate reverse osmosis membrane", Journal of Membrane Science, 188(2), pp. 173-179, 2001. https://doi.org/10.1016/S0376-7388(01)00353-2

[5] Balyan, U., Sarkar, B. "Integrated membrane process for purification and concentration of aqueous Syzygium cumini (L.) seed extract", Food and Bioproduct Processing, 98, pp. 29-43, 2016 httpss://doi.org/10.1016/j.fbp.2015.12.005

[6] Zhao, S., Yao, S., Ou, S., Lin, J., Wang, Y., Peng, X., Yu, B. "Preparation of ferulic acid from corn bran: Its improved extraction and purification by membrane separation", Food and Bioproduct Processing, 92(3), pp. 309-313, 2014

httpss://doi.org/10.1016/j.fbp.2013.09.004

[7] Urošević, T., Povrenović, D., Vukosavljević, P., Urošević, I., Stevanović, S. "Recent developments in microfiltration and ultrafiltration of fruit juices", Food and Bioproduct Processing, 106, pp. 147-161, 2017.

httpss://doi.org/10.1016/j.fbp.2017.09.009

[8] Chun, Y., Mulcahy, D., Zou, L., Kim. I. S. "A Short Review of Membrane Fouling in Forward Osmosis Processes", Membranes, 7(2), p. 30, 2017. https://doi.org/10.3390/membranes7020030

[9] Lee, J. S., Heo, S. A., Jo, H. J., Min, B. R. "Preparation and characteristics of cross-linked cellulose acetate ultrafiltration membranes with high chemical resistance and mechanical strength", Reactive and Functional Polymers, 99, pp. 114-121, 2016. https://doi.org/10.1016/j.reactfunctpolym.2015.12.014

[10] Peev, G., Penchev, P., Peshev, D., Angelov G. "Solvent extraction of rosmarinic acid from lemon balm and concentration of extracts by nanofiltration: Effect of plant pre-treatment by supercritical carbon dioxide", Chemical Engineering Research and Design, 89(11), pp. 2236-2243, 2011.

https://doi.org/10.1016/j.cherd.2011.04.014
Department and Excellent Applied Research Higher Education grant under Ministry of Research, Technology and Higher Education 2018.

[11] Kim, J. F., Gaffney, P. R., Valtcheva, I. B., Williams, G., Buswell, A. M., Anson, M. S., Livingston, A. G. "Organic Solvent Nanofiltration (OSN): A New Technology Platform for LiquidPhase Oligonucleotide Synthesis (LPOS)", Organic Process Research \& Development, 20(8), pp. 1439-1452, 2016. https://doi.org/10.1021/acs.oprd.6b00139

[12] Boam, A., Meniconi, A., Wu. X. "Membrane-based processes for selectively fractionating essential oils", U.S. Patent Application, No. 14/399, 273, 2013.

[13] Tylkowski, B., Trusheva, B., Bankova, V., Giamberini, M., Peev, G., Nikolova, A. "Extraction of biologically active compounds from propolis and concentration of extract by nanofiltration", Journal of Membrane Science, 348(1-2), pp. 124-130, 2010 https://doi.org/10.1016/j.memsci.2009.10.049

[14] Carlson, L. H. C., Bolzan, A., Machado, R. A. F. "Separation of d-limonene from supercritical CO2 by means of membrans", The Journal of Supercritical Fluids, 34(2), pp. 143-147, 2005. https://doi.org/10.1016/j.supflu.2004.11.007

[15] Sarmento, L. A. V., Spricigo, C. B., Petrus, J. C. C., Carlson, L. H. C., Machado, R. A. F. "Performance of reverse osmosis membrans in the separation of supercritical CO2 and essential oils", Journal of Membrane Science, 237(1-2), pp. 71-76, 2004. https://doi.org/10.1016/j.memsci.2004.02.021

[16] Nasution, I. K., Susilo, B., Nugroho, W. A. "Uji Kinerja Alat Pemurni Minyak Atsiri Daun Cengkeh (Clove Leaf Oil) berbasis Membran Kitosan-Selulosa" (Performance test of chitosan-cellulose membrane based clove leaf essential oil purifier), Jurnal Keteknikan Pertanian Tropis dan Biosistem, 2(1), 2013. (in Indonesian) [online] Available at: https://jkptb.ub.ac.id/index.php/ jkptb/article/view/167 [Accessed: 03 December 2018]

[17] Bing, N. C., Chen, Q., Zhu, L. P., Wang, L. L., Wang, L. J. "Effect of Swelling on Performance of Surface-Imprinted Composite Membranes", IOP Conference Series: Materials Science and Engineering, 170(1), ID: 012030, 2017. https://doi.org/10.1088/1757-899X/170/1/012030

[18] Solomon, M. F. J., Bhole, Y., Livingston, A. G. "High flux hydrophobic membrans for organic solvent nanofiltration (OSN)Interfacial polymerization, surface modification and solvent activation", Journal of Membrane Science, 434, pp. 193-203, 2013. https://doi.org/10.1016/j.memsci.2013.01.055

[19] Soroko, I., Livingston, A. "Impact of TiO2 nanoparticles on morphology and performance of crosslinked polyimide organic solvent nanofiltration (OSN) membranes", Journal of Membrane Science, 343(1-2), pp. 189-198, 2009.

https://doi.org/10.1016/j.memsci.2009.07.026

[20] Ng, H. K. M., Leo, C. P., Abdullah, A. Z. "Selective removal of dyes by molecular imprinted $\mathrm{TiO} 2$ nanoparticles in polysulfone ultrafiltration membrane", Journal of Environmental and Chemical Engineering, 5(4), pp. 3991-3998, 2017. https://doi.org/10.1016/j.jece.2017.07.075 
[21] Xu, Y. C., Tang, Y. P., Liu, L. F., Guo, Z. H., Shao, L. "Nanocomposite organic solvent nanofiltration membrans by a highly-efficient mussel-inspired co-deposition strategy", Journal of Membrane Science, 526, pp. 32-42, 2017. https://doi.org/10.1016/j.memsci.2016.12.026

[22] Zhang, Q., Zhang, C., Xu, J., Nie, Y., Li, S., Zhang, S. "Effect of poly(vinyl alcohol) coating process conditions on the properties and performance of polyamide reverse osmosis membranes", Desalination, 379, pp. 42-52, 2016. https://doi.org/10.1016/j.desal.2015.10.012

[23] Zhao, Y., Yuan, Q. "Effect of membran pretreatment on performance of solvent resistant nanofiltration membranes in methanol solutions", Journal of Membrane Science, 280(1-2), pp. 195-201, 2006.

https://doi.org/10.1016/j.memsci.2006.01.026

[24] Yin, J., Fan, H., Zhou, J. "Cellulose acetate/poly(vinyl alcohol) and cellulose acetate/crosslinked poly(vinyl alcohol) blend membrans: preparation, characterization, and antifouling properties", Desalination and Water Treatment, 57(23), pp. 10572-10584, 2016.

https://doi.org/10.1080/19443994.2015.1040846

[25] Kusworo, T. D., Aryanti, N., Quadratun, Utomo, D. P. "Oilfield produced water treatment to clean water using integrated activated carbon-bentonite adsorbent and double stages membrane process", Chemical Engineering Journal, 347, pp. 462-471, 2018. httpss://doi.org/10.1016/j.cej.2018.04.136

[26] Yu, X., Mi, X., He, Z., Meng, M., Li, H., Yan, Y. "Fouling resistant $\mathrm{CA} / \mathrm{PVA} / \mathrm{TiO} 2$ imprinted membranes for selective recognition and separation salicylic acid from waste water", Frontiers in Chemistry, 5, 2017. https://doi.org/10.3389/fchem.2017.00002

[27] Chakrabarty, B., Ghoshal, A. K., Purkait, M. K. "SEM analysis and gas permeability test to characterize polysulfone membran prepared with polyethylene glycol as additive", Journal of Colloid and Interface Science, 320(1), pp. 245-253, 2008. https://doi.org/10.1016/j.jcis.2008.01.002

[28] Mehrotra, R. "Infrared Spectroscopy, Gas Chromatography/ Infrared in Food Analysis", In: Meyers, R. A. (ed.) Encyclopedia of Analytical Chemistry, John Wiley \& Sons, Ltd., Chicester, UK, 2000, pp. 4007-4024. https://doi.org/10.1002/9780470027318.a1013

[29] Panda, S. R., De, S. "Preparation, characterization and performance of $\mathrm{ZnCl} 2$ incorporated polysulfone (PSF)/polyethylene glycol (PEG) blend low pressure nanofiltration membranes", Desalination, 347, pp. 52-65, 2014. https://doi.org/10.1016/j.desal.2014.05.030

[30] Singh, S., Khulbe, K. C., Matsuura, T., Ramamurthy, P. "Membran characterization by solute transport and atomic force microscopy", Journal of Membrane Science, 142(1), pp. 111-127, 1998. https://doi.org/10.1016/S0376-7388(97)00329-3

[31] Panda, S. R., De, S. "Role of polyethylene glycol with different solvents for tailor-made polysulfone membranes", Journal of Polymer Research, 20(7), p. 179. 2013. https://doi.org/10.1007/s10965-013-0179-4
[32] Yi, Y. D., Bae, Y. C. "Swelling behaviors of proton exchange membranes in alcohols", Polymer, 130, pp. 112-123, 2017. https://doi.org/10.1016/j.polymer.2017.09.069

[33] National Standard of Indonesia "SNI 06-2387-2006 Quality standard of clove oil product", National Standardization Council, Indonesia, 2006.

[34] Rachman, M. S., Pratiwi, L., Hidayati, N. "Ektraksi Minyak Atsiri dari Bunga Cengkeh dengan Pelarut Etanol dan N-Heksana" (Essential oil extraction from clove bud using etanol and n-hexane as solvents), The 3rd University Research Colloquium, pp. 655-661, 2016. (in Indonesian) [online] Available at: http:// eprints.ums.ac.id/66388/1/Jurnal\%20Publikasi\%20Ferry.pdf [Accessed: 03 December 2018]

[35] Jirovetz, L., Buchbauer, G., Stoilova, I., Stoyanova, A., Krastanov, A., Schmidt, E. "Chemical composition and antioxidant properties of clove leaf essential oil", Journal of Agricultural and Food Chemistry, 54(17), pp. 6303-6307, 2006. https://doi.org/10.1021/jf060608c

[36] Muhammed, A., El-Hashash, M. A., Mekewi, M. A., Guirguis, D. B., Ramadan, R.,Hassanien, M. A. H. "Polyvinyl alcohol-cellulose acetate composite reverses osmosis membranes: I. synthesis and characterization", Hydrology: Current Research, 3, p. 131, 2012. https://doi.org/10.4172/2157-7587.1000131

[37] Vatanpour, V., Madaeni, S. S., Khataee, A. R., Salehi, E., Zinadini, S., Monfared, H. A. "TiO2 embedded mixed matrix PES nanocomposite membranes: Influence of different sizes and types of nanoparticles on antifouling and performance", Desalination, 292, pp. 19-29, 2012.

https://doi.org/10.1016/j.desal.2012.02.006

[38] Kusworo, T. D., Utomo, D. P., Aryanti, N., Quadratun "Synergistic effect of UV irradiation and thermal annealing to develop high performance polyethersulfone-nano silica membrane for produced water treatment", Journal of Environmental Chemical Engineering, 5(4), pp. 3290-3301, 2017. https://doi.org/10.1016/j.jece.2017.06.035

[39] Kusworo, T. D., Soetrisnanto, D., Utomo, D. P. "Development of Nano-hybrid Cellulose Acetate/TiO2 Membrane for Eugenol Purification from Crude Clove Leaf Oil", MATEC Web of Conferences, 156, ID: 08013, 2018. https://doi.org/10.1051/matecconf/201815608013

[40] Geens, J., Van der Bruggen, B., Vandecasteele, C. "Characterisation of the solvent stability of polymeric nanofiltration membranes by measurement of contact angles and swelling", Chemical Engineering Science, 59(5), pp. 1161-1164, 2004. https://doi.org/10.1016/j.ces.2004.01.003

[41] Jhaveri, J. H., Murthy, Z. V. P. "A comprehensive review on anti-fouling nanocomposite membranes for pressure driven membrane separation processes", Desalination, 379, pp. 137-154, 2016. https://doi.org/10.1016/j.desal.2015.11.009

[42] Ismail, A. F., Kusworo, T. D., Mustafa, A. "Enhanced gas permeation performance of polyethersulfone mixed matrix hollow fiber membranes using novel Dynasylan Ameo silane agent", Journal of Membrane Science, 319(1-2), pp. 306-312, 2018. https://doi.org/10.1016/j.memsci.2008.03.067 